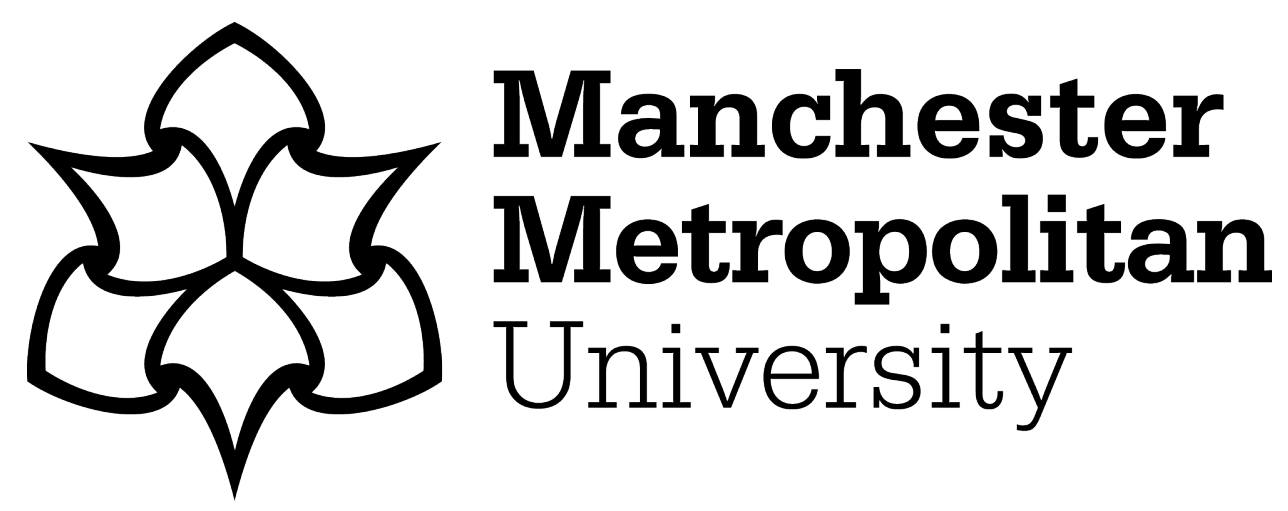

Jung, Timothy ORCID logoORCID: https://orcid.org/0000-0002-8594-6641, tom Dieck, Mandy ORCID logoORCID: https://orcid.org/0000-0002-87658969, Lee, Hyunae and Chung, Namho (2020) Moderating Role of Longterm Orientation on Augmented Reality Adoption. International Journal of Human-Computer Interaction, 36 (3). pp. 239-250. ISSN 1044-7318

Downloaded from: https://e-space.mmu.ac.uk/623076/

Version: Accepted Version

Publisher: Taylor \& Francis

DOI: https://doi.org/10.1080/10447318.2019.1630933

Please cite the published version 


\section{The Moderating Role of Long-term Orientation on Augmented Reality Adoption}

\section{Timothy Jung, Ph.D.}

Faculty of Business and Law, Manchester Metropolitan University, Righton Building, Cavendish Street, Manchester M15 6BG, England

Email: t.jung@mmu.ac.uk, Tel: +44 161-247-2701

\section{Claudia tom Dieck*, Ph.D.}

Faculty of Business and Law, Manchester Metropolitan University Righton Building, Cavendish Street, Manchester M15 6BG, England

Email: c.tom-dieck@mmu.ac.uk, Tel: +44 161-247-2724

\section{Hyunae Lee}

Department of Hotel Management, Graduate School, Kyung Hee University

26 Kyunghee-daero, Dongdaemun-gu Seoul 02447, Republic of Korea

E-mail: halee8601@khu.ac.kr, Tel: +82-2-961-2353, Fax: +82-2-961-9557

\section{Namho Chung, Ph.D.}

College of Hotel \& Tourism Management, Kyung Hee University 26 Kyunghee-daero, Dongdaemun-gu, Seoul 02447, Republic of Korea Email: nhchung@khu.ac.kr, Tel: +82-2-961-2353 Fax: +82-2-961-9557

\footnotetext{
*Corresponding Author
} 


\title{
Moderating Role of Long-term Orientation on Augmented Reality Adoption
}

\begin{abstract}
Recently, the tourism and hospitality industry is providing tourists with an enhanced experience via various cutting-edge technologies such as augmented reality (AR). In addition, there has been an increased interest on the effects of cultural traits on human behaviours. The aim of this paper is to examine how Long- and Short-term orientation moderates the relationship between experience economy provided by AR applications and users' perceived value. Data were collected from 145 participants at Deoksugung Palace in Seoul, South Korea and 119 participants at An Post Museum, Dublin, Ireland. We found that South Korean tourists, who are representatives of long-term orientation culture in this study, put a high value on educational factors of AR applications, whereas Irish tourists, who are representative of short-term orientation culture, regard escapist experiences of AR applications highly.
\end{abstract}

Keywords Augmented Reality, Long-term Orientation, Cultural difference, Experience economy

\section{Introduction}

Numerous information technologies (ITs) such as augmented reality (AR) and virtual reality (VR) have been developed and used in tourism destinations in order to provide tourists with destination-related information and fun (Guttentag, 2010; Haugstvedt and Krogstie, 2012). Unlike VR, which provides users with a complete virtual environment, AR provides virtually superimposed images on the real world view (Rauschnabel, 2018; Rauschnabel et al., 2017). Therefore, AR not only enhances the real world, but also 
enables users to be immersed in a virtually enhanced real world (Bujak et al., 2013; Di Serio et al., 2013). According to Juniper Research's Augmented Reality 2015-2019 report, AR revenue is expected to increase from 184 million US dollars to 1.3 billion US dollars by 2019 (ITProPortal, 2015). While numerous academic studies have investigated the relationships between user's perception or experience and acceptance of AR (e.g. Jung et al., 2015; Rauschnabel \& Ro, 2016; tom Dieck et al., 2018), tourism destinations around the world have started to actively develop and utilize AR applications.

An important precursor of technology acceptance in tourism and hospitality is user's experience, which led to the development of the experience economy by Pine and Gilmore in 2010. Oh et al. (2007) revealed that the experience economy belongs to the fastest growing sectors. Tourism and hospitality studies have long acknowledged the importance of creating memorable experiences (Kang and Gretzel, 2012; Park et al., 2010; Quan and Wang, 2004) thus, the move towards an experience economy comes as no surprise (Knutson et al., 2010). Pine and Gilmore (1999) included education, (a)esthetics, entertainment and escapist as the four realms of the experience economy. According to Oh et al. (2007, p. 127), the 'four realms of experience offer not only conceptual fit but also a practical measurement framework for the study of tourist experiences'. Furthermore, Oh et al. (2007) emphasized the importance of incorporating the four realms into conceptual tourist experience models in order to clarify the applicability of education, (a)esthetics, entertainment and escapist in various tourism contexts. Particularly in the area of AR, only limited research exists within the tourism and hospitality context. 
Furthermore, there has been a small number of cross-cultural research to investigate the different perceptions and experiences of using AR applications in tourism destinations (e.g. Jung et al., 2018), notwithstanding there has been an increased interest on the effects of cultural characteristics on human behaviour and phenomena by a number of researchers (Venaik et al., 2013). According to Hofstede and Bond (1988), it is important to measure and compare cultural differences in order to identify values and beliefs that differentiate countries from one another. In the context of technology acceptance, the process of accepting and using a specific technology may depend on user's own culture (Harris et al., 2005). According to Jung et al. (2018), tourists from a high power distance, high uncertainty avoidance and collectivism culture tend to use AR in tourism destinations when they perceive usability, enjoyment and social influence, whereas tourists from low power distances, low uncertainty avoidance and individualism cultures tend to use AR when they perceive that it is easy to use. Therefore, a lack of understanding of the cultural differences can prevent tourism practitioners to properly utilize various technologies (Tsang and Ap, 2007). In addition, as stated above, little attention has been paid to how different the process of users' AR acceptance is based on tourists' cultural backgrounds (e.g. Harris et al., 2005). Thus, this study aims to investigate the differences in the technology acceptance process of tourists from diverse cultures.

Five cultural dimensions were developed by Hofstede (1980) and Hofstede and Bond (1988): (1) Masculinity/Femininity, (2) Power distance, (3) Individualism/Collectivism, (4) Uncertainty avoidance and (5) Long/Short-term orientation. Among them, Long-term orientation refers to 'the degree to which people's actions are driven by Long-term goals and results, rather than the Short-term results and the 
need for immediate gratification' (Ardichvili and Kuchinke, 2002, p. 100), and was added since it can explain the economic growth of many East Asian countries (e.g. South Korea, Japan, China, and so on) Hofstede and Bond, 1988). Therefore, notwithstanding globalization, it can be assumed that Long-term orientation is the best dimension enabling us to distinguish the Asian and non-Asian culture. Further, Long-term orientation has its roots in Confucian values placing high focus on pragmatic rules, time, tradition, perseverance, thrift, trying to acquire skills and education, working hard and allowing others to 'save face' for future's goals and results (Hofstede and Bond, 1988; Ardichvili and Kuchinke, 2006; Bearden, Money, and Nevins, 2006; Hofstede and Minkov, 2010). This can affect the way of people perceive, experience, and behave when facing any social changes including technological advances. Therefore, in the context of acceptance of AR, it can be inferred that the process from individuals' perception to acceptance in long-term orientation culture can be different from that in short-term orientation culture.

Previous studies examined Hofstede's cultural factors (individualism/collectivism, power distance, uncertainty avoidance, and masculinity/femininity) (Crotts and Erdmann, 2000; Litvin et al., 2004), but very little research was conducted regarding Long/Short-term orientation. For instance, Jung et al. (2018) explored the effects of cross-cultural differences on mobile AR adoption within the cultural heritage tourism context however, missed to incorporate Long-and Short-term orientation as a cultural dimension.

The important part in cross-cultural research is to select target countries. In order to minimize the biased impacts of other factors such as social, technological, geological, and so forth, countries with similar level of aforementioned factors, but remarkably different cultural profiles (Jung et al., 2018). For 
instance, Cho and Cheon (2015) used four countries (the United States, the United Kingdoms, South Korea and Japan) with the greatest advertising revenues, but different cultural profiles. In the context of $\mathrm{AR}$, the smartphone penetration rate is an important factor for using the AR application. Therefore, the present study selected two countries: South Korea and Ireland which have high level of smartphone penetration (72\% for South Korea, 57\% for Ireland) (Richter, 2013), but remarkably different cultural profiles (South Korea features Long-term orientation whereas Ireland features Short-term orientation) (Hofstede, 2000). Smartphone penetration is important when considering AR, as mobiles are the most widely used devices in order to access AR content while travelling (tom Dieck and Jung, 2018).

Consequently, the aim of this paper is to examine how Long- and Short-term orientation moderates the relationship between experience economy provided by AR application and users' perceived value, which consequently induce tourist's intention to use AR.

The current study presents a review of literature on augmented reality in tourism, experience economy, perceived value and long term orientation. A theoretical model is presented and hypotheses proposed. Moreover, the two stages of data collection in Korea and Ireland using AR applications in cultural heritage sites are discussed and analysed using partial least square analysis. Findings are then, discussed, and theoretical and practical considerations provided. Finally, the models will serve as a future reference point for industry practitioners and academia who are aiming to implement $A R$ into the tourism experience.

\section{Literature Review}




\section{Augmented reality in tourism and museums}

Recently, the tourism industry has been providing tourists with enhanced touristic experience by combining various cutting-edge information communication technologies (ICTs) which can encourage whole genres of experience economy (Pine and Gilmore, 1998). Especially AR has been regarded as one of the most useful technologies for enhancing tourists' experience in destinations. Several prior researches have investigated the relationship between users' experience and AR (e.g. Fritz et al., 2005; Kounavis et al., 2012; Olsson and Salo, 2011). A considerable number of AR applications have been actively developed and provided by arts and cultural heritage institutions or organizations around the world in order to dispense archaeological information by combining real resources with virtual images and information (Fritz et al., 2005; Ridel et al., 2014). Thus, AR can not only prevent physical degradation of arts and cultural heritage destinations aggravated by frequent access by tourists but also give numerous opportunities to achieve knowledge about history and joyfulness (Tussyadiah et al., 2017). According to Kounavis et al. (2012), AR applications enhance both utilitarian and hedonic experiences of tourists. In other words, AR applications are useful to fulfil different requirements of tourists such as the attractiveness, user-friendliness, educational value, and reusability (Fritz et al., 2005; tom Dieck and Jung, 2018). Recently, numerous museum and cultural heritage journals started to publish on the opportunities of AR for the enhancement of the visitor experience. For instance, Moorhouse et al. (2019) explore the use of AR for the learning experience within small and medium sized museums and found that $\mathrm{AR}$ helps to create experiential learning experience, creating a novel and authentic museum learning environment. Similarly, Southall et al. (2019) supported AR's strength in creating engaging cultural heritage experience and added that AR creates personalised experiences. 


\section{Experience Economy}

In order to meet customers' needs of seeking unique experience rather than simply consuming products or services, the paradigm of businesses have been shifted from focusing on products or services to emphasizing 'staged' experiences in order to create memorable experiences (Pine and Gilmore, 1998;

Oh et al., 2007). 'Staged' experience is an essential element of tourism, in other words, productive activity of tourism is the creation of touristic experience (Sternberg, 1997). Since then, numerous researches have applied the experience economy concept to tourism (Charters et al., 2009; Cho et al., 2002; Kounavis et al., 2012; Mehmetoglu and Engen, 2011; Oh et al., 2007; Park, Oh and Park, 2010). However, although previous research has combined the tourism industry with information technology (IT), there are few studies about tourists' IT experiences at destinations.

Meanwhile, Pine and Gilmore (1998) divided this 'staged' experience into four realms (or dimensions) of experience which can be distinguished by two spectrums of participation (passive and active participation) and connection (absorption and immersion): entertainment, educational, (a)esthetic, and escapist experience (Figure. 1). The following sentences provide definitions for the experience economy constructs. Esthetics can be defines as "the beauty that can be expressed though the elements such as color, photographs, font style, and layout" (Lee et al., 2015, p. 481). Education is defined as "The absorption of "events unfolding before [a tourist] at a destination, while actively participating through interactive engagement of the mind" (Oh et al., 2007, p. 121). Entertainment is "an activity that provides amusement and pleasure" (Benny, 2005, p.7). Finally, escapism refers to the "escape of regular 
environments to suspend the power of norms and values that govern their ordinary lives or to think about their lives and societies from a different perspectives" (Oh et al., 2007, p. 122).

In the tourism context, a tourist with educational experiences tends to be eager to increase their knowledge and skills at a tourism destination (Oh et al., 2007). Cultural heritage tourism is one of the most important places served by AR applications (Adhani and Awang, 2012; Portalés, Lerma and Pérez, 2009). AR provides its users with destination-related historical and geological information on the real world view captured from the camera. For instance, an AR application named 'Deoksugung in my hands' launched in Deoksugung Palace, which is one of the royal palace in South Korea, provides historical information of the palace, a distance from the location of the user to specific building of the palace and point-of-interest. Thus, tourists can enhance their knowledge about the destination by using the AR application. Meanwhile, (a)esthetics and escapism experience have a feature of immersion which is defined as 'becoming physically or virtually a part of the experience itself' (Pine and Gilmore, 1988, p. 31). A tourist with (a)esthetic experience tends to be 'indulged in environments' (Oh et al., 2007, p. 4), and a tourist with escapism experience tends to be 'diverging to a new self' (Oh et al., 2007, p. 4). AR application enables tourists to be fully immersed in tourism destinations (Jung et al., 2018) by providing high quality $3 \mathrm{D}$ images and information which is superimposed on the real world view (Azuma et al., 2001; Kounavis et al., 2012). AR applications launched at cultural heritage tourism destinations have been generally designed to offer historical and geological information in a 3D graphic and fascinating form in order not to bore tourists. 
More recently, an increasing number of studies started to investigate the experience economy concept within the tourism and hospitality context (Hosany and Witham, 2009; Loureiro, 2014; Manthou et al, 2014; Mehmetoglu and Engen, 2011; Neuburger and Egger, 2017; Oh et al., 2007). This study aims to extend previous research on the experience economy within the tourism context in a number of ways. First, this study aims to include cultural differences as part of the experience economy framework in order to understand and explains how cultural traits influence the adoption of AR, an area previously not explored. In addition, previous experience economy studies explored the effect on satisfaction (Hosany and Witham, 2009; Mehmetoglu and Engen), memory and arousal (Manthiou et al., 2014). However, the effect of experience economy on perceived value is relatively unexplored, which will be a second contribution of this paper. This is particularly important considering that perceived value is considered one of the critical dimensions in marketing literature, even previously discussed to replace satisfaction (Eggert and Ulaga, 2002).

Please insert Figure 1 about here

\section{Perceived value}

The creation of value was thoroughly discussed in business strategy literature and is perceived as one of the key success factors to long-term profitability (Peppard and Ward, 2016). According to Chen and Chen (2010, p. 30), perceived value refers to 'the consumer's overall assessment of the utility of a product (or service) based on perceptions of what is received and what is given'. Furthermore, perceived value is an important indicator of business success within the marketing literature (Eggert and Ulaga, 2002). 
According to tom Dieck and Jung (2017, p. 111), 'research is required to investigate the association of consumers' perceived value with innovative digital services such as AR [...] to create business models that reflect the significant impact of consumer value on the delivery of information systems'. Poncin and Mimoun (2014) reiterated the need for including perceived value as part of the customer experience due to its strong tendency to predict behaviours and intentions. Scholars started to explore the concept of perceived value within the experience economy idea. For instance, Wu and Liang (2007, p. 588) defined experiential value as the 'value [that] is derived from how a product creates appropriate experiences, feelings and emotions in a customer'. With this in mind, there is limited research that integrates perceived value into a structural experience economy model and thus, the present study aims to address this gap in tourism and hospitality literature.

\section{Long-term orientation}

There have been a number of studies looking at the issue of cultural differences in various IS adoption contexts. For instance, Proctor et al. (2019) revealed that the design of digital media needs to consider cultural differences from across the globe in order to be successful, in particularly with regards to differences in decision making. Similarly, Rossi et al. (2019) confirmed that as part of project management, cultural differences play an immensely important role in terms of software adoption. Heimgaertner (2013) confirmed that software designers needs to incorporate cultural differences into human computer interaction. Also within the tourism context, cultural differences are recognised as an important area of investigation as in general, tourists tend to seek the touristic experiences related to their cultural background (Landauer et al., 2013). Especially, combined with various IS which have the role of enhancing tourists' experience, tourism industry is facing an increasing number of inbound tourists 
who have different cultural backgrounds (Pine and Gilmore, 1998; Tsang and Ap, 2007). Meanwhile, cultural difference can be a barrier for tourists to accept IS (Lee, 2013) and the process of IS acceptance depends on the culture (Harris et al., 2005). Thus, a cross-cultural approach about IS acceptance is needed (Di Serio et al., 2013; Harris et al., 2005).

One of the most widely used dimensions for measuring and comparing cultural characteristics among the countries are the 'five dimensions' of Hofstede (1980) and Hofstede and Bond (1988). In 1980, Hofstede (1980) proposed four dimensions of measuring national culture: individualism/collectivism, power distance, uncertainty avoidance and masculinity/femininity. After that, focusing on fast economic growth of East Asian countries such as South Korea, China and Japan, Hofstede and Bond (1988) added Longterm orientation dimension because they regarded Long-term orientation as one of the most powerful driving forces of economic growth of many East Asian countries. Contrary to Short-term orientation of many Western countries which focuses on need for immediate gratification (Ardichvili and Kuchinke, 2006) and hedonic value (Mattila, 1999), Long-term orientation has its roots in Confucian values concerning time, tradition, perseverance, thrift, trying to acquire skills and education, working hard, and allowing others to 'save face' for future's goals or results (Ardichvili and Kuchinke, 2006; Bearden et al., 2006; Hofstede and Minkov, 2010).

Jung et al. (2018) explored the effect of cross-cultural differences on mobile AR adoption within the cultural heritage tourism context focusing on masculinity/feminity, power distance, individualism/collectivism and uncertainty avoidance however, neglected to incorporate Long- and Short 
term orientation into their structural model. Their findings confirmed strong cultural differences with regards to AR adoption and thus, application design and implementation needs to be planned according to target markets in order to ensure acceptance. However, considering that their study missed to incorporate long- and short term orientation, further research is required to look into the effects of this cultural dimension.

Please insert Table 1 about here

\section{Research model and hypotheses}

Based on the aforementioned literature review, we proposed the following research model (Figure 2). First, the impacts of four realms of experience economy on perceived value and intention to use AR will be demonstrated with the main hypotheses from $\mathrm{H}_{1}$ to $\mathrm{H}_{5}$. Further, we will estimate the moderating role of Long-term orientation with two divided subgroups: South Korea and Ireland were regarded as representative of Long-term orientation culture and Short-term orientation, respectively.

Please insert Figure 2 about here

Oh et al. (2007) stated that research, incorporating education, (a)esthetics, entertainment, and escapism into a structural model is limited. Chen and Chen (2010) identified that experience quality has a positive effect on perceived value which ultimately influences the intention to use. There are a number of 
empirical studies who used all or some of the four pillars of the experience economy and found evidence on their effect on perceived value. For instance, firstly, education has received relatively little attention for its effect on perceived value. Two studies found an effect of information quality/reliability on perceived value (Chung and Ko, 2015; Han et al., 2016), however the path of education towards perceived value is unexplored and opens new avenues for investigation. Arguably it could be considered that people gather information as part of education which concurs with Ghani et als' (2014, p. 297) definition of education being 'a process of acquiring information and formulation of the product of the learning process'. Secondly, Xu et al. (2015, p. 180) strengthened the importance of a(esthetics) on perceived value stating 'given the effect of app aesthetics on value formation, app developers should focus on interface design to ensure that the apps are visually aesthetic'. Thirdly, in the mobile context, $\mathrm{Xu}$ et al. (2009) found strong support for the effect of entertainment on the perceived value. However, already Choi (2012, p. 241) revealed that cultural differences may affect this path as his study revealed that the 'impact of entertainment on value perception is very small in China, when comparing it to the USA'. This leads to interesting questions with regards to cultural dimensions also incorporated in our proposed model. Finally, the effect of escapism on perceived value has been confirmed in a number of contexts. For instance, Mathwick et al. (2002) confirmed that escapism is an indicator of perceived value within the retail context. Turel et al. (2010) conducted a study on the adoption of digital artefacts and found that escapism influences users' hedonic values. In addition, perceived value has commonly supported the intention to use services in the tourism context (Chen and Chen, 2010; Cronin et al., 2000; Petrick, 2004) however, research incorporating the four experience economy dimensions is scarce (Oh et al., 2007) and therefore, the following hypotheses are proposed: 
$\mathrm{H}_{1:}$ Education has a positive effect on perceived value.

$\mathrm{H}_{2}$ (A)Esthetics has a positive effect on perceived value.

$\mathrm{H}_{3}$ : Entertainment has a positive effect on perceived value.

$\mathrm{H}_{4}$ : Escapism has a positive effect on perceived value.

$\mathrm{H}_{5}$ : Perceived value has a positive effect on the intention to use.

As stated above, among the five cultural dimensions proposed by Hofstede (1980) and Hofstede and Bond (1988), Long-term orientation can be regarded as the best cultural dimension for distinguishing Asian cultures and non-Asian cultures since it was developed in order to explain the fast economic growth of Asian cultures (Hofstede and Bond, 1988). In this vein, some previous research has investigated the moderating effect of Long (Short)-term orientation in the relationships between corporate social responsibility (CSR) and new ventures' financial performance (Wang and Bansal, 2012), between reward time (immediate/accumulate) or type (monetary/non-monetary) of restaurant's reward program and customer loyalty (Park et al., 2013), and between information diversity and civic virtue (Yu and Cable, 2011). However, compared to first four cultural difference dimensions, not enough attention has been paid to the Long (Short)-term orientation.

The things that people put their value on are different according to their cultural background. Individuals from Long-term orientation cultures tend to believe that they should prepare and work hard for realizing their future dreams, whereas individuals from Short-term orientation tend to put a high value on the 
present (Park et al., 2013). In the context of IT acceptance such as AR, the valuation criteria that individuals put a high value on may be different according to their cultural background. Originally, individuals' perceived value refers to 'the consumer's overall assessment of the utility of a product (or service) based on perceptions of what is received and what is given' (Cohen and Cohen, 2010, p. 30). In this study, we conceptualized perceived value as tourist's overall assessment of the utility of AR application at tourism destinations based on perception of what is received and what is given.

To be more specific, it is possible to infer that individuals from Long-term orientation culture which puts emphasis on the education tend to more perceive the value of knowledge or information provided by AR application rather than individuals from Short-term orientation culture. Given that individuals in Longterm orientation culture tend to avoid spending more than necessary (Hofstede and Bond, 1988), it can be inferred that these people may not care much about or even may feel annoyed by the esthetic, entertainment and escapism aspects of AR. On the other hand, it can be assumed that individuals from Short-term orientation culture which regards the present as important perceive the value of fascinating features or interface quality of AR application rather than individuals from Short-term orientation culture. Therefore, the following hypotheses are proposed:

H1a: The effect of education on perceived value is stronger within Long-term orientation cultures. $\mathrm{H} 2 \mathrm{~b}$ : The effect of a(e)sthetics on perceived value is stronger on Short-term orientation cultures. H3c: The effect of entertainment on perceived value is stronger on Short-term orientation cultures. H4d: The effect of escapism on perceived value is stronger on Short-term orientation cultures. 


\section{Methodology}

\section{Study context}

The study was conducted at two sites in order to explore cultural differences. The first part of the study was conducted at Deoksugung palace, one of the traditional royal palaces in South Korea. The second part of the study was conducted at An Post Museum, one of the historic buildings at Dublin's independence trail. Both of these sites have launched AR applications which were called 'Deoksugung in my hands' and 'Dublin AR' respectively. The two AR applications were chosen for this study, as they had similar design and functionalities and were both designed for Android devices. AR content was triggered through object recognition in both cases with the aim of enhancing the visitor experience in an unobtrusive way. In fact, both AR applications had a similar structure, design, interface and role of providing their users with historical information and joyfulness at the same time. Triggered AR content included audio, video and text information.

\section{Data collection}

Considering that most visitors were not aware of the possibility to use these AR applications as part of the museum experience, we provided study participants with a manual to familiarise themselves with the applications. We took a convenience sampling process and asked visitors to read the manual and to use the AR apps in Deoksugung Palace and An Post Museum for about 30 minutes before participating in the survey. All of the participants were offered a gift certificate worth about USD 5. A total number of 145 questionnaires were collected at Deoksugung Palace and 119 questionnaires were collected at An 
Post Museum. Out of total respondents of Deoksugung Place, 94 (64.8 \%) were female, and 51 (35.2\%) were male; about half of respondents were between 20 and 29 (46.2\%) or students (60.0\%). In An Post Museum, out of 136 respondents, 98 (82.4\%) were female, and 21 (17.6\%) were male; most of the respondents were 29 below (92.4\%) or students (89.9\%). Although the respondents of these surveys were young and high-educated, only $48(33.1 \%)$ and $11(9.1 \%)$ respondents of South Korea and Ireland had ever used AR respectively.

\section{Measurement items}

Measurement items used for this study were adopted from previous literature; measurement items of the four realms of experience economy (Oh et al., 2007), perceived value (Van der Heijden, 2004) and intention to use AR (Venkatesh et al., 2003). This procedure yielded 27 measurement items including four realms of experience economy (twenty items), perceived value (four items), and intention to use AR (three items) (Table 3). With respect to four realms of experience economy, individual indicated the degree to which they agreed the statements of each experience (i.e., Education: "The experience by using the AR application has made me more knowledgeable", Esthetics: "When I used AR application, I felt a real sense of harmony", Entertainment: "Using the AR application was enjoyable", Escapist: "By using the AR application, I felt like I played a different character"). To assess perceived value, individuals were asked to respond to the statements (i.e., "I can choose which attraction to look at quicker and easier using the AR application"). Finally, in order to measure intention to use AR, the respondents answered the three statements (i.e., "I intend to use the AR application in the future"). All items were measured on a seven-point Likert scale with strongly disagree (1) and strongly agree (7). 
The questionnaire was developed in English and then translated into Korean by Ph.D students and professors who have academic specialisation and are proficient in both languages. Any material discrepancies were found in the questionnaire.

\section{Results}

In order to test the proposed research model, we used a partial least squares (PLS) regression analysis, using PLS-Graph Version 3.0. PLS regression analysis has several advantages, including small sample size, and few assumptions about measurement scale and normal distribution (Ahuja and Thatcher, 2005). Using PLS-Graph, the measurement model and structural model were estimated.

\section{Measurement Model}

The measurement model was assessed separately for the full sample and each subgroup (Long-term orientation group and Short-term orientation group). Confirmatory factor analysis was first conducted. To validate our measurement model, we undertook validity assessments of content, convergent and discriminant validity. First, the content validity of our survey was established from the previous literature, and we patterned our measures on the constructs validated by other previous researchers. Second, convergent validity can be established by calculating composite reliability (CR), Cronbach's alpha, and the average variance extracted (AVE) (Bhattacherjee and Sanford 2006). These values should be greater than the thresholds (Cronbach's alpha $>=0.7, \mathrm{CR}>=0.7$ and AVE $>=0.5$ ) (Table 2). In other words, all of the constructs used in our research model satisfied the requirements, thus, convergent validity could be established. Finally, the discriminant validity of the measurement model can be established when the 
square root of the AVE is greater than the correlations between the construct and other construct. The square root of the AVE for each construct exceeded the correlations between that construct and other construct (Table 3). Thus, the results established that the item demonstrated discriminant validity. 
Please insert Table 2 about here

Please insert Table 3 about here

\section{Overall model}

We estimated three separate models by using PLS graph: the full sample, Long-term orientation group and Short-term orientation group. After then, we tested for differences across all three models using the test for differences. The size of bootstrapping sample that was used in the PLS analyses was 500 . In terms of the main hypotheses $\left(\mathrm{H}_{1}-\mathrm{H}_{5}\right)$, as shown in Table 4, perceived value is influenced by education $(\beta=0.414, \mathrm{t}=4.676, \mathrm{p}<0.001)$ and (a)esthetics experience $(\beta=0.219, \mathrm{t}=2.503, \mathrm{p}<0.05)$, whereas it is not influenced by entertainment $(\beta=0.089, \mathrm{t}=0.979$, n.s. $)$ and escapist experience $(\beta=0.020, \mathrm{t}=0.408$, n.s. $)$. Thus, hypotheses 1, 2 and 5 were supported, whereas hypotheses 3 and 4 were not supported. Then, we estimated separated model: South Korea (Long-term orientation) and Ireland (Short-term orientation). As expected, among the four realms of experience economy, education experience was found to be the strongest predictor of perceived value in South Korea. However, unlike the overall model, education, (a)esthetics, entertainment experience has no influence on perceived value in Ireland. Only escapist experience was found to marginally influence perceived value $(\mathrm{p}<0.1)$ (Table 4).

Please insert Table 4 about here

Moderating effect of Long(Short)-term Orientation 
In order to examine the moderating effect of Long (Short)-term orientation, a multi-group analysis using PLS was conducted by comparing differences in the coefficients of the corresponding structural paths for the Long-term orientation group and Short-term orientation group (Chin, 2007; Keil et al., 2000). The results show that the coefficients from each path for education and escapist experience were significantly different between Long-term orientation group and Short-term orientation group, whereas (a)esthetics and entertainment experience were not significantly different between those groups (Table 5). Test for hypotheses $\mathrm{H}_{1}$ and $\mathrm{H}_{4 a}$ demonstrate that the impact of education experience (Long-term orientation: $0.666>$ Short-term orientation: $0.185, \Delta \mathrm{t}=-3.095)$ and escapist (Long-term orientation: $-0.088<$ Shortterm orientation: $0.186, \Delta \mathrm{t}=2.528$ ), were statistically different between Long-term orientation group and Short-term orientation group. Therefore, when using the AR application in cultural heritage tourism destinations, South Korean tourists (Long-term orientation) tend to put high value on education, whereas Ireland tourists (Short-term orientation) tend to emphasis on escapist experience. However, both the path from (a)esthetic and entertainment experience to perceived value were not significantly different between two countries, thus, hypotheses $\mathrm{H}_{2 \mathrm{a}}$ and $\mathrm{H}_{3}$ a were not supported.

Please insert Table 5 about here

\section{Discussion and Conclusion}

\section{Discussion}

The aim of this paper was to examine the moderating effect of Long (Short)-term orientation on the relationship between experience economy provided by AR application and users' perceived value. A 
previous study looked at Hofstede's cultural factors in the context of AR (Jung et al., 2018) and the present study adds to the existing pool of knowledge by exploring the effect of Long and Short-term orientation. In fact, this study empirically tested the impact of cultural difference (Long/Short-term orientation) on the effects of the experience dimensions onto the perceived value of AR applications. Our model proved that tourists from Long-term orientation culture highly regard on the educational factor of AR, while ones from Short-term orientation culture consider the escapism factor of AR when they use AR applications at tourism destinations. Considering the limited research on the experience economy incorporating the importance of cultural differences, this study provides important implications for the development and implementation of AR applications in the tourism context. Secondly, this paper added the dimension of perceived value into the experience economy framework, thus added another theoretical contribution.

Tom Dieck and Jung (2017) called for further research on perceived value within the tourism AR context, and the present study found that perceived value mediates the effect of experiences and behavioural intentions, supporting Poncin and Mimoun (2014). In addition, the results represented that the effects of the four realms of experience economy on perceived value and intention to use AR at tourism destinations depend on tourists' cultural background. To be more specific, we found that South Korean tourists representative of Long-term orientation culture in this study put a high value on educational factor of AR application, whereas Irish tourists representative of Short-term orientation culture in this study regard escapist experience of AR application. Those two findings are supported by the definition of Ardichvili and Kuchinke (2002) stating that Eastern cultures are more driven by Long-term goals, while Western 
cultures are more concerned with instant gratification. A finding also supporting a study by Chin from 2012, who found that entertainment influences perceived value within Western cultures, however less so in high power distance, collectivist and long term orientation cultures (similar to South Korea). Similarly, Mattila (1999) proposed that Western cultures are more concerned with hedonic values. However, this could not be supported within the present study as we did not find evidence for a significant difference on the relationships of entertainment and (a)esthetics towards the perceived value. Evidently, this seems to be one of the biggest differences compared to previous research. Nevertheless, this study has clearly shown that there are evident differences in terms of the value of education and escapism and cultural heritage destination marketing managers need to be aware of these differences to create their AR marketing strategies accordingly.

\section{Theoretical contributions}

The present study has a number of theoretical contributions. First, the study used the experience economy to explicitly look at cultural differences with regards to technology adoption, an area that has not previously been explored within the hospitality and tourism context. Second, this study incorporated perceived value into the experience economy framework while previously studies focused on satisfaction, arousal or memory, this study revealed the importance of perceived value to enhance behavioural intentions within the tourism and hospitality context, incorporating suggestions from an earlier study by Eggert and Ulaga (2002) on the increased effect of perceived value on business success. Third, an increasing number of travellers uses AR application while travelling hence, research in this area adds to the much needed pool of knowledge on AR adoption behaviour. Finally, this study added to 
existing research on the effect of cultural differences on tourists' adoption of AR by exploring the effects of Long- and Short-term orientation (Jung et al., 2018).

\section{Practical Implications}

There are a number of interesting implications that can be drawn from these findings. Thinking about the value of providing AR applications for tourists, museums, attractions and destinations in Eastern cultures have to strongly focus on the educational value of their applications as Asian tourists, from a Long-term orientation culture, tend to associate the value of an application through its educational potential. Interestingly, this needs also to be taken into account by Western cultural heritage destinations due to increased number of Asian tourists visiting European destinations. Most of the cultural heritage destinations around the world have been providing several guide services from traditional ones (e.g. map, audio guide and leaflet) to new ones combined with cutting-edge technologies (e.g. AR and VR). In order to satisfy tourists from Long-term orientation cultures and let them use AR, AR is required to provide more accurate and plentiful information rather than other guide services. This study furthermore supported Western culture's strong demand for escapism, as the need to become someone else or entering a new world strongly influenced the value perception of the AR application within the Irish context. This finding also needs to be considered by East cultural heritage destinations. Since numerous guide services of East cultural heritage destinations tend to focus on delivering information, relatively little attention has been paid to the escapism factors of it. Therefore, in order to satisfy tourists from Short-term orientation cultures and let them use AR, destinations are required to provide more immersive settings by offering high-quality and high-resolution $3 \mathrm{D}$ graphic images. In addition, app developers need to 
minimise stutter within AR applications which obstructs tourists' immersion and sense of having a useful and valuable experience.

\section{Limitations and Future Research}

Notwithstanding the implications, the present study has some limitations. Due to the novelty factor, mostly young and well-educated people participated in this study, which makes it difficult to generalise the findings to a wider population. In addition, the two aforementioned applications were designed slightly differently in terms of content and visual layout due to the two different attractions, one being a palace and one a museum. Therefore, in particular the unsupported hypothesis with regards to (a)esthetics might be related to application design. In the future, it is recommended to build the same application with only slightly different content for the same context (either museums or other visitor attraction) to fully test the cultural effects of (a)esthetics. Finally, this study used Hofstede's fifth cultural dimension (long term orientation) to explore cultural differences in AR app usage among museum visitors in Ireland and South Korea. Future research should take a more nuanced approach and consider international visitors who might not fit the dimension and therefore application design should take a holistic approach. Further, future research should consider Hofstede's sixth dimension (indulgence versus self-restraint) to explore cultural differences in terms of immersive tech adoption,

\section{References}


Ahuja, M. K., \& Thatcher, J. B. (2005). Moving beyond intentions and toward the theory of trying: Effects of work environments and gender on post-adoption information technology use. MIS Quarterly, 29(3), 427-459.

Ardichvili, A., \& Kuchinke, K. P. (2002). Leadership styles and cultural values among managers and subordinates: a comparative study of four countries of the former Soviet Union, Germany, and the US. Human Resource Development International, 5(1), 99-117.

Azuma, R. T. (1997). A survey of augmented reality. Presence, 6(4), 355-385.

Azuma, R., Baillot, Y., Behringer, R., Feiner, S., Julier, S., \& MacIntyre, B. (2001). Recent advances in Augmented Reality. Computer Graphics and Applications, 21(6), 34-47.

Bearden, W. O., Money, R. B. \& Nevins, J. L. (2006). A measure of long-term orientation: Development and validation. Journal of the Academy of Marketing Science. 34(3), 456-467.

Benny, L. K. W. (2015). Entertainment Studies-A Perspective. American International Journal of Research in Humanities, Arts and Social Sciences, 7-11

Bhattacherjee, A. \& Sanford, C. (2006). Influence processes for information technology acceptance: an elaboration likelihood model, "MIS quarterly. 30(4), 805-825.

Bujak, K. R., Radu, I., Catrambone, R., MacIntyre, B., Zheng, R. \& Golubski, G. (2013). A psychological perspective on augmented reality in the mathematics classroom. Computers \& Education, 68, 536-544.

Charters, S., Fountain, J. \& Fish, N. (2009). You Felt Like Lingering...” Experiencing “Real” Service at the Winery Tasting Room. Journal of travel research, 48(1), 122-134. 
Chen, C. F., \& Chen, F. S. (2010). Experience quality, perceived value, satisfaction and behavioral intentions for heritage tourists. Tourism management, 31(1), 29-35.

Chin, W.W. (2007. Frequently asked questions - partial least squares and PLS-graph. Retrieved from http://disc-nt.cba.uh.edu/chin/plsfaq/plsfaq.htm

Cho, Y. H., Wang, Y., \& Fesenmaier, D. R. (2002). Searching for experiences: The web-based virtual tour in tourism marketing. Journal of Travel \& Tourism Marketing, 12(4), 1-17.

Choi, E. J. (2012). Online Shopping Model for Luxury Goods.. e-비즈니스 연구, 13(2), 241-258.

Chung, N. \& Koo, C. (2015). The use of social media in travel information search. Telematics and Informatics, 32(2), 215-229.

Cronin, J. J., Brady, M. K., \& Hult, G. T. M. (2000). Assessing the effects of quality, value, and customer satisfaction on consumer behavioral intentions in service environments. Journal of retailing, 76(2), 193-218.

Crotts, J. C., \& Erdmann, R. (2000). Does national culture influence consumers' evaluation of travel services? A test of Hofstede's model of cross-cultural differences. Managing Service Quality: An International Journal, 10(6), 410-419.

Di Serio, Á., Ibáñez, M. B., \& Kloos, C. D. (2013). Impact of an augmented reality system on students' motivation for a visual art course. Computers \& Education, 68, 586-596.

Eggert, A., \& Ulaga, W. (2002). Customer perceived value: a substitute for satisfaction in business markets?", Journal of Business and industrial marketing, 17(2/3), 107-118. 
Fritz, F., Susperregui, A., \& Linaza, M. T. (2005). Enhancing cultural tourism experiences with augmented reality technologies, 6th International Symposium on Virtual Reality, Archaeology and Cultural Heritage (VAST).

Ghani, K., Kamarudin, M., Kamis, S., \& Yussof, N. (2014). Relationship between the practice of J-QAF teachers and individual of authority towards supporting the arabic assessment (PKSR). Mediterranean Journal of Social Science, 5(16), 296-301.

Guttentag, D. A. (2010). Virtual reality: Applications and implications for tourism. Tourism Management, 31(5), 637-651.

Han, H., Park, A., Chung, N. \& Lee, K. J. (2016). A near field communication adoption and its impact on Expo visitors' behavior. International Journal of Information Management, 36(6), 1328-1339.

Harris, P., Rettie, R., \& Cheung, C. K. (2005). Adoption and usage of m-commerce: a cross-cultural comparison of Hong Kong and the United Kingdom. Journal of Electronic Commerce Research, $6(3), 210-224$.

Haugstvedt, A. C. \& Krogstie, J. (2012). Mobile augmented reality for cultural heritage: A technology acceptance study. In Mixed and Augmented Reality (ISMAR), in the proceedings of 2012 IEEE International Symposium on (pp. 247-255). IEEE.

Heimgärtner, R. (2013). Reflections on a model of culturally influenced human-computer interaction to cover cultural contexts in HCI design. International Journal of Human-Computer Interaction, 29(4), 205-219.

Hofstede, G. (1980). Culture and organizations. International Studies of Management \& Organization, $10(4), 15-41$. 
Hofstede, G. \& Bond, M. H. (1988). The Confucius connection: From cultural roots to economic growth. Organizational dynamics, 16(4), 5-21.

Hofstede, G. (2005). Cultures and organization: Software of the mind (2nd ed.). McGraw-Hill: NY.

Hofstede, G. \& Minkov, M. (2010). Long-versus short-term orientation: new perspectives. Asia Pacific Business Review, 16(4), 493-504.

Hosany, S. \& Witham, M. (2010). Dimensions of cruisers' experiences, satisfaction, and intention to recommend. Journal of Travel Research, 49(3), 351-364.

ITProPortal. (2015). Juniper Research: Augmented reality set to increase by 2019. Retrieved from http://www.itproportal.com/2015/04/02/juniper-research-augmented-reality-set-increase-2019/

Jung, T., Chung, N. \& Leue, M. C. (2015). The determinants of recommendations to use augmented reality technologies: The case of a Korean theme park. Tourism management, 49, 75-86.

Jung, T., Lee, H., Chung, N. \& tom Dieck, M.C. (2018). Cross-Cultural Differences in Adopting Mobile Augmented Reality at Cultural Heritage Tourism Sites. International Journal of Contemporary Hospitality Management, 30(8).

Kang, M. \& Gretzel, U. (2012). Effects of podcast tours on tourist experience in a national park. Tourism Management, 22(2), 440-455.

Keil, M., Tan, B. C., Wei, K. K., Saarinen, T., Tuunainen, V. \& Wassenaar, A. (2000). A cross-cultural study on escalation of commitment behavior in software projects. MIS Quarterly, 24(2), 299-325.

Knutson, B. J., Beck, J. A., Kim, S. \& Cha, J. (2010). Service quality as a component of the hospitality experience: Proposal of a conceptual model and framework for research. Journal of Foodservice Business Research, 13(1), 15-23. 
Kounavis, C. D., Kasimati, A. E., Zamani, E. D. \& Giaglis, G. M. (2012). Enhancing the tourism experience through mobile augmented reality: Challenges and prospects. International Journal of Engineering Business Management, 4(10), 1-6.

Landauer, M., Haider, W. \& Pröbstl-Haider, U. (2013). The influence of culture on climate change adaptation strategies: preferences of cross-country skiers in Austria and Finland. Journal of Travel Research, doi: 10.1177/0047287513481276.

Lee, L. Y. S. (2013). Hospitality Industry Web-Based Self-Service Technology Adoption Model: A Cross-Cultural Perspective. Journal of Hospitality \& Tourism Research, doi: $10.1177 / 1096348013495695$.

Lee, H., Chung, N., and Jung, T. (2015). Examining the Cultural Differences in Acceptance of Mobile Augmented Reality: Comparison of South Korea and Ireland, In Tussyadiah, I. and Inversini, A. (Eds). Information and Communication Technologies in Tourism (pp. 477-491). Springer Computer Science, Vienna.

Lin, P. H., \& Yeh, S. C. (2019). How Motion-Control Influences a VR-Supported Technology for Mental Rotation Learning: From the Perspectives of Playfulness, Gender Difference and Technology Acceptance Model. International Journal of Human-Computer Interaction, 1-11.

Litvin, S. W., Crotts, J. C. \& Hefner, F. L. (2004). Cross-cultural tourist behaviour: a replication and extension involving Hofstede's uncertainty avoidance dimension. International Journal of Tourism Research, 6(1), 29-37.

Loureiro, S. M. C. (2014). The role of the rural tourism experience economy in place attachment and behavioral intentions. International Journal of Hospitality Management, 40, 1-9. 
Manthiou, A., Lee, S., Tang, L. \& Chiang, L. (2014). The experience economy approach to festival marketing: Vivid memory and attendee loyalty. Journal of Services Marketing, 28(1), 22-35.

Mathwick, C., Malhotra, N. K. \& Rigdon, E. (2002). The effect of dynamic retail experiences on experiential perceptions of value: an Internet and catalog comparison. Journal of retailing, 78(1), $51-60$.

Mattila, A. S. (1999). The role of culture in the service evaluation process. Journal of service research, 1(3), 250-261.

Mehmetoglu, M. \& Engen, M. (2011). Pine and Gilmore's concept of experience economy and its dimensions: An empirical examination in tourism. Journal of Quality Assurance in Hospitality \& Tourism, 12(4), 237-255.

Moorhouse, N., tom Dieck, M. C., \& Jung, T. (2019). An experiential view to children learning in museums with Augmented Reality. Museum Management and Curatorship, 1-17.

Neuburger, L. \& Egger, R. (2017). An Afternoon at the Museum: Through the Lens of Augmented Reality. in Schegg, R. and Stangl, B. (Eds.). Information and Communication Technologies in Tourism 2017 (pp. 241-254). Springer, Heidelberg.

Oh, H., Fiore, A. M. \& Jeoung, M. (2007). Measuring experience economy concepts: Tourism applications. Journal of Travel Research, 46(2), 119-132.

Olsson, T. \& Salo, M. (2011). Online user survey on current mobile augmented reality applications", in Mixed and Augmented Reality (ISMAR), 2011 10th IEEE International Symposium on (pp. 7584). IEEE. 
Park, S. B., Chung, N. \& Woo, S. C. (2013). Do reward programs build loyalty to restaurants? The moderating effect of long-term orientation on the timing and types of rewards. Managing Service Quality: An International Journal, 23(3), 225-244.

Park, M., Oh, H. \& Park, J. (2010). Measuring the experience economy of film festival participants. International Journal of Tourism Sciences, 10(2), 35-54.

Pine, B. J. \& Gilmore, H. J. (1999). The Experience Economy: Work is Theatre \& Every Business a Stage. Boston, MA: Harvard Business School Press.

Pine, B. J. \& Gilmore, J. H. (1998). Welcome to the experience economy. Harvard business review, 76, 97-105.

Petrick, J. F. (2004). The roles of quality, value, and satisfaction in predicting cruise passengers' behavioral intentions. Journal of travel research, 42(4), 397-407.

Proctor, R. W., Nof, S. Y., Yih, Y., Balasubramanian, P., Busemeyer, J. R., Carayon, P., ... \& Landry, S. J. (2011). Understanding and improving cross-cultural decision making in design and use of digital media: A research agenda. Intl. Journal of Human-Computer Interaction, 27(2), 151-190.

Quan, S. \& Wang, N. (2004). Towards a structural model of the tourist experience: An illustration from food experiences in tourism. Tourism Management, 25(3), 297-305.

Rauschnabel, P. A. (2018). Virtually enhancing the real world with holograms: An exploration of expected gratifications of using augmented reality smart glasses. Psychology \& Marketing, 35(8), $557-572$.

Rauschnabel, P. A., \& Ro, Y. K. (2016). Augmented reality smart glasses: An investigation of technology acceptance drivers. International Journal of Technology Marketing, 11(2), 123-148. 
Rauschnabel, P., Rossmann, A. \& tom Dieck, M.C. (2017). An Adoption Framework for Mobile Augmented Reality Games: The Case of Pokémon Go. Computers in Human Behavior, 76, 276286.

Ridel, B., Reuter, P., Laviole, J., Mellado, N., Couture, N., \& Granier, X. (2014). The revealing flashlight: Interactive spatial augmented reality for detail exploration of cultural heritage artifacts. Journal on Computing and Cultural Heritage, 7(2), 1-17.

Richter, F. (2013). The United States Ranks 13th in Smartphone Penetration”, Statista. Retrieved from http://www.statista.com/chart/1405/the-united-states-ranks-13th-in-smartphone-penetration/

Russo, P., Lanzilotti, R., Costabile, M. F., \& Pettit, C. J. (2018). Adoption and use of software in land use planning practice: A multiple-country study. International Journal of Human-Computer Interaction, 34(1), 57-72.

Southall, H., Marmion, M., \& Davies, A. (2019). Adapting Jake Knapp's Design Sprint Approach for AR/VR Applications in Digital Heritage. In tom Dieck, M.C. \& Jung, T. (Eds.), Augmented Reality and Virtual Reality (pp. 59-70). Springer, Cham.

Sternberg, E. (1997). The iconography of the tourism experience. Annals of Tourism Research, 24(4), 951-969.

Portalés, C., Lerma, J. L. \& Pérez, C. (2009). Photogrammetry and augmented reality for cultural heritage applications. The Photogrammetric Record, 24(128), 316-331.

tom Dieck, M. C., \& Jung, T. H. (2017). Value of augmented reality at cultural heritage sites: A stakeholder approach. Journal of destination marketing \& management, 6(2), 110-117. 
tom Dieck, M. C. \& Jung, T. (2018). A theoretical model of mobile augmented reality acceptance in urban heritage tourism. Current Issues in Tourism, 21(2), 154-174.

tom Dieck, M. C., Jung, T. H., \& Rauschnabel, P. A. (2018). Determining visitor engagement through augmented reality at science festivals: An experience economy perspective. Computers in Human Behavior, 82, 44-53.

Tsang, N. K. F. \& Ap, J. (2007). Tourists' perceptions of relational quality service attributes: A crosscultural study. Journal of Travel Research, 45(3), 355-363.

Turel, O., Serenko, A. \& Bontis, N. (2010). User acceptance of hedonic digital artifacts: A theory of consumption values perspective. Information \& Management, 47(1), 53-59.

Tussyadiah, I. P., Jung, T. H. \& tom Dieck, M. C. (2017). Embodiment of Wearable Augmented Reality Technology in Tourism Experiences. Journal of Travel Research, 0047287517709090.

van der Heijden, H. (2004). User acceptance of hedonic information systems. MIS quarterly, 28(4), 695704.

Wang, T. \& Bansal, P. (2012). Social responsibility in new ventures: profiting from a long-term orientation. Strategic Management Journal, 33(10), 1135-1153.

Venaik, S., Zhu, Y. \& Brewer, P. (2013). Looking into the future: Hofstede long term orientation versus GLOBE future orientation. Cross Cultural Management: An International Journal, 20(3), 361385.

Xu, C., Peak, D. \& Prybutok, V. (2015). A customer value, satisfaction, and loyalty perspective of mobile application recommendations. Decision Support Systems, 79, 171-183. 
Xu, H., Oh, L. B. \& Teo, H. H. (2009). Perceived effectiveness of text vs. multimedia location-based advertising messaging. International Journal of Mobile Communications, 7(2), 154-177.

Yu, K. Y. T. \& Cable, D. M. (2011). Unpacking cooperation in diverse teams: Incorporating long-term orientation and civic virtue in the study of informational diversity. Team Performance Management, 17(1/2), 63-82. 


\section{Timothy Jung}

Timothy Jung is Director of Augmented and Virtual Reality Hub, Manchester Metropolitan University, UK. He is the Chair of the International Augmented and Virtual Reality Conference and his research interests include augmented reality, virtual reality and immersive technologies.

\section{Claudia tom Dieck}

M. Claudia tom Dieck is a researcher at the Creative Augmented and Virtual Reality Hub at Manchester Metropolitan University. Her research interests include immersive technologies in the hospitality and tourism context. She is the program chair of the annual International Augmented and Virtual Reality Conference.

Hyunae Lee is a student majoring in tourism at Kyung Hee University, Seoul. She received her bachelor degree in tourism management at Gachon (Kyungwon) University. Her research interests include the role of information systems in pre-decision, decision and post-purchase evaluation of tourists.

Namho Chung is a professor at the College of Hotel \& Tourism Management and the director of Smart Tourism Research Center (STRC) at Kyung Hee University in Seoul. His research interests include travel behavior, information search and decision making, and the development of information systems for Destination Management Organizations. 